\title{
Digital Nomadism: the nexus of remote working and travel mobility
}

\author{
Inge Hermann ${ }^{1}$ D $\cdot$ Cody Morris Paris ${ }^{2}$ D
}

(c) Springer-Verlag GmbH Germany, part of Springer Nature 2020

\section{Introduction}

As the world went into lockdown due to the COVID-19 pandemic outbreak, people worldwide started to experience a 'new normal.' This 'new normal' has normalized remote-working and resulted in the mainstream adoption of technologies to support virtual collaboration, communication, and work from a distance. While the COVID19 pandemic resulted in the restriction of mobility as borders were closed, airlines grounded, and daily commutes limited, visions of a potential future of 'remote-life' started to take shape. As professionals (and employers) around the world start to realize that they are no longer physically secured to their desks, offices, or work stations, they may now start to consider a future where they are remote-working from 'exotic' locations, often with lower costs of living (Phuket, Bali, or Costa Rica?) instead of working from 'home.' Companies around the world have extended their remote-working policies, implemented due to COVID, through 2021 and beyond, and are starting to consider a broader shift towards remote (or hybrid) workforce models as a means for reducing overhead costs while supporting employee productivity and wellbeing.

The impacts of the COVID pandemic have rippled throughout the tourism industry. Even as the industry starts a long road to recovery, there will likely be lasting impacts. Business travel has been disrupted and will likely evolve in its post-COVID form, particularly with the 'remote' alternative and likely increase in travel costs (at least in the short term). Companies dependent on business travelers (particularly in the accommodation sector) will need to evolve as well. With travel restrictions in place and regulations frequently changing for entry/exit procedures (quarantining, COVID testing, etc.), most destination countries face a long road to recover to

Inge Hermann

i.hermann@rocva.nl

Cody Morris Paris

c.paris@mdx.ac.ae

1 ROC van Amsterdam-Flevoland, Amsterdam, The Netherlands

2 Middlesex University Dubai, Dubai, United Arab Emirates 
pre-pandemic arrival numbers. Several countries, including Estonia, Georgia, Bermuda, and Barbados (Table 1), have recently introduced a new type of visa that allows longer-term visits for remote-workers. In other words, they are establishing "digital nomad" visas that provide residency (up to 1 year) to location-independent workers that allows them to work or run their business from the country regardless of the location or time zone of that business.

The COVID-19 pandemic may have accelerated the digital nomad phenomenon's normalization first predicted by Makimoto and Manners (1997) more than 20 years ago. This special issue brings together five papers focused on further deciphering the digital nomad phenomenon. While the call for papers for this special issue and much of the research included was completed prior the COVID-19 pandemic, the special issue engages with some very relatable and timely research questions contributing to the academic inquiry into the interdependence of mobility and technology that will continue to be of fundamental importance for current and future tourism practices (Hannam et al. 2014).

Table 1 Digital Nomad Visa 'Welcomes' from Bermuda and Barbados (September, 2020)

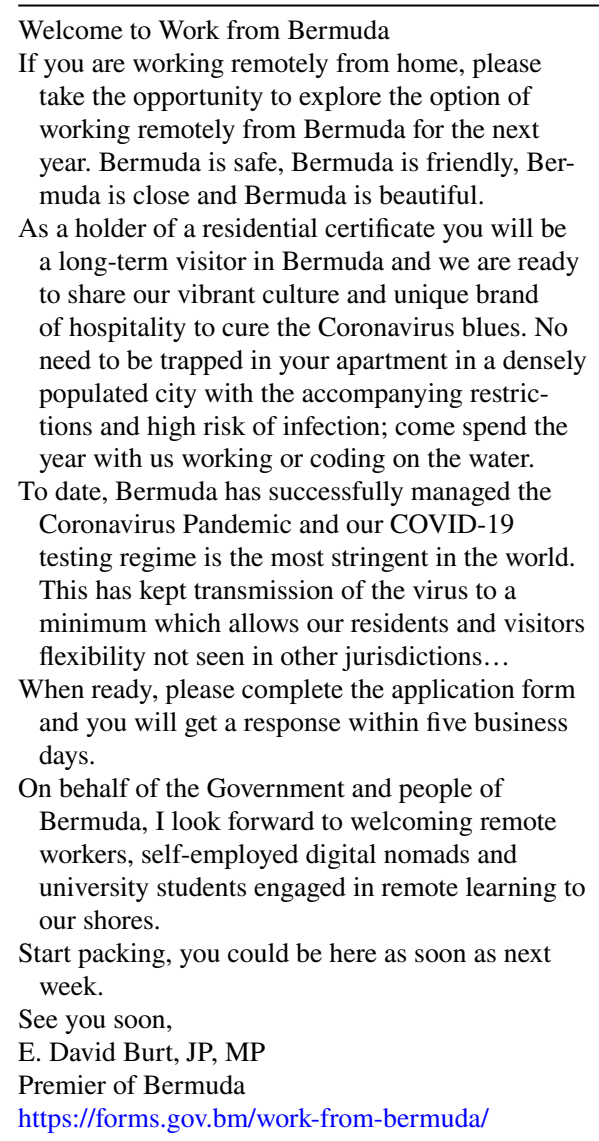

Welcome to Barbados!

On behalf of our beautiful island of Barbados, I would like to extend a warm welcome to you. Although the COVID 19 pandemic has been a tremendous challenge to people around the world, we believe it has also opened up opportunities.

We recognise more people are working remotely, sometimes in very stressful conditions, with little option for vacation. Our new 12 month Barbados Welcome Stamp, a visa that allows you to relocate and work from one of the world's most beloved tourism destinations.

We believe we have something very special to offer on this little rock we call Barbados. Our friendly people, professional services, commitment to education and importantly safety and security, all make Barbados an ideal place to live for both singles and families.

Thank you for considering making Barbados your new home.

Blessings,

Mia Amor Mottley, Q.C., M.P.

Prime Minister of Barbados

https://www.barbadoswelcomestamp.bb/ 


\section{Digital nomads}

When Tsugio Makimoto and David Manners published their future-looking manifesto Digital Nomads in 1997, they envisioned a globalized world in which new technologies, new kinds of work arrangements, and a growing emphasis on entrepreneurial practices would radically change our lives, blurring distinctions between work, leisure, home, and travel. They argued that companies would continue to adapt to be competitive in the (virtual) global market place, and, as a result, people would be forced to choose whether to live the life of a settler or nomad (Makimoto and Manners, 1997). Today, more than 20 years later, their vision of a world in which people would be liberated from daily commuting to/from their office cubicles has indeed become a reality for many, be it either by choice or involuntary (Thompson, 2019).

Situated within a broad range of mobile lifestyles practices and lifestyle migration patterns are those of location-independent workers, often referred to as "digital nomads," who can work almost anywhere, anytime, thanks to the ubiquity of digital infrastructure and technological advances (Blatt and Gallagher 2013). The urge to be "location independent" is often associated with a search for (personal) freedom, adventure, and an escape from the traditional work environment (Müller 2016; Reichenberger 2018; Sutherland and Jarrahi 2017). While nomadic workers typically travel by their work, digital nomads travel while working and, therefore, instead of moving merely between spaces and locations for work, digital nomads also have to be flexible around whatever spaces they find in the locations they choose to travel (Nash et al. 2018). In doing so, movement between places is driven by a quest for the "good life" rather than purely employment opportunities (Müller 2016).

Although it is difficult to pinpoint a specific number of digital nomads (particularly in the midst of the COVID-19 pandemic), a study in 2018 by MBO illustrates the rise of this particular lifestyle movement: rough estimations are up to 4.8 million digital nomads in the United States (MBO 2018) alone. However, as the number of long-term remote workers continues to rise globally, the number of digital nomads will continue to grow. Furthermore, a Google.com search on ["digital nomads"] in September 2020 generated 5,700,000 generic results (up from 1,300,000 generic results in January 2019). The search provided a glance of the content of various news articles and popular press, websites, blog posts, tutorials, and social media posts, many of which seem to elucidate the compelling notion that traveling the globe while working remotely is something everyone can or-as some argueshould act on in their pursuit for a better, or at least different, way of life.

Digital nomads are symbolic of the contemporary liquid society in which individuals are continuously 'on the move' (Bauman 2006; Urry 2007; Müller 2016; Reichenberger 2018; Sutherland and Jarrahi 2017). Seemingly, what makes the lifestyle so befitting and appealing for many is a combination of several broader structural trends, including globalization, technological innovations, and the shifting arrangements of work and social life. Although these developments can be challenging for many around the world, as work becomes more flexible, precarious, and often low paid, they play out rather well for digital nomads who 
embrace this new (labor) landscape in their pursuit for more autonomy, flexibility, and excitement outside of work (Altringer 2015). Conversely, despite its alternative lifestyle aura, digital nomadism does not necessarily disrupt institutional structures, social expectations, or daily routines that define contemporary life. However, instead, digital nomads adapt to neoliberal changes by using their entrepreneurial thinking and technological skills to construct their lifestyle.

In addition to being geographically mobile, digital nomads often move between different jobs and positions to sustain their remote lifestyle. The proliferation of information and communication technologies (ICTs) has provided digital nomads with professional flexibility and adaptability tools. Therefore, contrary to prior representations of nomadic travelers, digital nomads should not, necessarily, be regarded as those living on the margins or outside "normal" society, but as those 'happy few' pursuing a lifestyle in which continuous participation in the labor force is combined with (and results in) a mobile life that holds purpose and meaning.

Digital nomads shape and reshape their professional and personal lives to uphold their desired lifestyle, blending work, and leisure with travel (Makimoto and Manners 1997; Urry 2007). Traditionally, digital nomads have been employed as freelancers, travel bloggers, or independent internet entrepreneurs in tech-(supported) fields, but more recently also become increasingly common in a range of other roles and sectors, with jobs ranging from web designer to language tutor, and from software engineer to virtual assistant. Nonetheless, for many digital nomads, the desire to travel has been the leading factor in choosing to live a nomadic lifestyle, leaving serious considerations on attaining sufficient location-independent income largely unattained at first. Coinciding with the growth of digital nomads seeking a location-independent lifestyle of work and travel, the market of intermediaries offering support services has grown. This includes mentorship programs, co-living, and cooffice space, domain-specific assistance (legal, technical), and agencies to help digital nomads kick-start their new mobile lifestyle. Alongside these secondary agents is an emergent cottage industry of nomads who fund their lifestyle by teaching others how to become a digital nomad. By transforming their mobile lifestyle narratives into a primary commodity - through coaching, blogging, organizing events, and retreats - their lifestyle strategy and practical knowledge have become a 'revenuegenerating system, aimed at other potentially like-minded people' (Mancinelli 2018: 317).

Despite being portrayed as beach-bound laptop workers with high levels of selfreliance and minimal constraints, digital nomads also must navigate the precariousness, high risks, loneliness, and uncertainty that comes with the lifestyle. In an attempt to overcome these issues, many seek to be around (but not necessarily interact with) like-minded others in exotic locations around the globe, such as Chiang Mai, Medellin, Ubud and Phuket. In response, companies have started offering (relatively) expensive, all-inclusive community settings such as co-living/co-working spaces, camps and cruises, providing digital nomads with a bubble-like comfortable, middle-class, Western environment in which visible social interactions can take place within any location around the global, though excluding the local population and cultural contexts (Thompson 2019). 
Due to digital nomadism's relative novelty, research is emergent and still fragmented (Schlagwein 2018; Reichenberger 2018; Müller 2016; Nash et al. 2018; Thompson 2019; Germann Molz and Paris 2015). In this special issue, we aimed to expand current knowledge of the digital nomad phenomenon and the interdependencies of technology and mobility at the work-leisure-travel nexus. Collectively, the contributors critically examine and debate current developments and issues (related to) digital nomadism through conceptual, theoretical, methodological, and empirical insights and may inform future directions for tourism research, policymaking, and daily practices.

von Zumbusch and Lalicic (2020) explore the role of co-living spaces in digital nomads' wellbeing. Through in-depth interviews, their study provides insights into the lived experiences of digital nomads in co-living spaces. With the recent growth of the co-living accommodation sector, insights from the study could inform the development and operation of co-living spaces.

Willment (2020)'s study is an engaging exploration of the workplace performances of digital nomadism among travel bloggers, engaging in issues of online self-presentation, authenticity, and place. The study demonstrated the inherent role of technology and the performance of digital nomadism for travel bloggers' work.

Cook (2020) critically examines the generic digital nomad idea of freedom, represented by an imagined lifestyle of tensionless work, leisure, and mobility. Employing a robust longitudinal ethnographic fieldwork that tracked sixteen digital nomads over a 4-year period, the study presents an insightful assessment of the reality of digital nomadism. In reality, digital nomadism requires high levels of discipline and self-disciplining practices to separate work and leisure time.

Mancinelli (2020) argues that digital nomadism is not an 'alternative' lifestyle challenging the status quo. Instead, it is an opportunistic adaptation to the neoliberal order, whereby digital nomads take advantage of privileged nationalities to navigate global inequalities in the capitalist system. Based on ethnographic research, the study contrasts the socio-cultural imaginaries of (in)mobility and the economic strategies employed to sustain continued mobility.

Olga (2020) wades through the somewhat fragmented and emerging literature on digital nomadism to provide some conceptual clarity of the digital nomad phenomenon. In doing so, she frames digital nomadism within lifestyle mobilities and examines the phenomenon within the context of other contemporary forms of locationindependent work and lifestyle-led mobility.

Thank you to all of the contributors to this special, including the authors and reviewers.

\section{References}

Altringer B (2015) Globetrotting digital nomads: the future of work or to good to be true? In Forbes leadership Forum

Bauman Z (2006) Liquid times. Polity Press, Cambridge

Blatt K, Gallagher J (2013) Mobile workforce: the rise of the mobilocracy. In: Bruck P, Rao M (eds) Global mobile: applications and innovations for the worldwide mobile ecosystem. Information Today, Inc., Medford, pp 275-292 
Cook D (2020) The freedom trap: digital nomads and the use of disciplining practices to manage work/ leisure boundaries. Inf Technol Tour. https://doi.org/10.1007/s40558-020-00172-4

Germann Molz J, Paris CM (2015) The social affordances of flashpacking: exploring the mobility nexus of travel and communication. Mobilities 10(2):173-192. https://doi.org/10.1080/17450 101.2013.848605

Hannam K, Butler G, Paris CM (2014) Developments and key issues in tourism mobilities. Ann Tour Res 44:171-185

Makimoto T, Manners D (1997) Digital nomad. Wiley, New York

Mancinelli F (2018) A practice of togetherness: home imaginings in the life of location-independent families. Int J Tour Anthropol 6(4):307-322

Mancinelli F (2020) Digital nomads: freedom, responsibility and the neoliberal order. Inf Technol Tour. https://doi.org/10.1007/s40558-020-00174-2

MBO (2018) Digital Nomadism: A Rising Trend. https://www.mbopartners.com/uploads/files/state-ofindependence-reports/StateofIndependence-ResearchBrief-DigitalNomads.pdf. Accessed $25 \mathrm{Feb}$ 2019

Müller A (2016) The digital nomad: buzzword or research category? Transl Soc Rev 6:344-348

Nash C, Jarrahi M, Sutherland W, Phillips G (2018) Digital nomads beyond the buzzword: defining digital nomadic work and use of digital technologies. Transform Digit Worlds 10766:207-217

Olga $H$ (2020) In search of a digital nomad: defining the phenomenon. Inf Technol Tour. https://doi. org/10.1007/s40558-020-00177-z

Reichenberger I (2018) Digital nomads-a quest for holistic freedom in work and leisure. Ann Leis Res 21(3):364-380. https://doi.org/10.1080/11745398.2017.1358098

Schlagwein D (2018) The history of digital nomadism. In: 6th international workshop on the changing nature of work CNOW 2018, San Francisco, USA. International workshop on the changing nature of work

Sutherland S, Jarrahi MH (2017) The gig economy and information infrastructure: the case of the digital nomad community. Proc ACM Hum Comput Interact. https://doi.org/10.1145/3134732

Thompson BY (2019) The digital nomad lifestyle: (remote) work/leisure balance, privilege, and constructed community. Int J Sociol Leis. https://doi.org/10.1007/s41978-018-00030-y

Urry J (2007) Mobilities. PolityUrry, Cambridge

von Zumbusch JSH, Lalicic L (2020) The role of co-living spaces in digital nomads' wellbeing. Inf Technol Tour. https://doi.org/10.1007/s40558-020-00182-2

Willment N (2020) The travel blogger as digital nomad: (Re-)imagining workplace performances of digital nomadism within travel blogging work. Inf Technol Tour. https://doi.org/10.1007/s40558-02000173-3

Publisher's Note Springer Nature remains neutral with regard to jurisdictional claims in published maps and institutional affiliations. 